\title{
Mortalitas dan Pertumbuhan Larva Nyamuk Anopheles aconitus kerena Pemberian Ekstrak Daun Selasih Oscimum basilicum
}

\author{
Istimuyasaroh, Mochamad Hadi, Udi Tarwotjo \\ Lab. Ekologi dan Biosistematik Jurusan Biologi FMIPA Undip
}

\begin{abstract}
Abstrak
Nyamuk Anopheles aconitus merupakan vektor penyakit malaria. Penyakit malaria merupakan penyakit infeksi yang sering terjadi di daerah tropis, salah satunya Indonesia. Pengendalian nyamuk Anopheles aconitus sebagai vektor perlu dilakukan secara tepat dan ramah lingkungan. Tanaman selasih (Oscimum basilicum) diketahui mempunyai potensi sebagai sumber bahan insektisida botani karena kandungan metabolit sekundernya, antara lain eugenol, linalool, dan geraniol yang diketahui tidak disukai oleh nyamuk. Tujuan penelitian adalah mengkaji mortalitas dan pertumbuhan larva nyamuk Anopheles aconitus akibat pemberian ekstrak daun selasih Oscimum basilicum serta mengetahui konsentrasi efektif ekstrak daun selasih dalam meningkatkan mortalitas serta menurunkan pertumbuhan larva nyamuk Anopheles aconitus. Penelitian dilaksanakan di Laboratorium Ekologi dan Biosistematik Jurusan Biologi F MIPA UNDIP. Data mortalitas diperoleh dengan uji hayati yang selanjutnya diuji dengan analisis probit untuk mengetahui efektifitas bahan uji. Sedangkan data pertumbuhan diolah dengan rumus Zhang. Hasil penelitian menunjukkan bahwa mortalitas larva meningkat sejalan dengan meningkatnya konsentrasi ekstrak. Efektifitas ekstrak terhadap larva uji ditunjukkan dengan tingkat toksisitas ekstrak (LC (00- 48 jam) adalah $5,01 \%$. Pertumbuhan larva juga menurun sejalan dengan meningkatnay konsentrasi ekstrak, nilai GI (Growth index) berkisar antara 1-0, dan nilai RGI (Relative growth index) berkisar antara 100-81\%.
\end{abstract}

Kata kunci : Oscimum basilicum, Anopheles aconitus, mortalitas, pertumbuhan

\section{PENDAHULUAN}

Selama ini pengendalian nyamuk Anopheles masih menggunakan insektisida kimia yang tidak ramah lingkungan dan berisiko terhadap resistensi nyamuk terhadap insektisida. Salah satu alternatif yang lebih ramah lingkungan adalah dengan memanfaatkan tanaman anti nyamuk. Salah satu tanaman anti nyamuk adalah selasih Oscimum basilicum yang mengandung eugenol, linalool, dan geraniol yang bersifat volatil, senyawa ini menyebabkan nyamuk enggan mendekat (Dinata, 2005). Senyawa-senyawa aktif yang terkandung dalan daun selasih antara lain eugenol, methyl eugenol, ocimene, alfa pinene, eucalyptol, linalool, geraniol, methyl cinnamate, anetol, dan chompor (Kardiman, 2003a).

Penggunaan selasih sebagai atraktan untuk mengendalikan hama lalat buah sudah diterapkan oleh para petani buah di Sumedang, Jawa Barat (Kardiman, 2003b). Sedangkan Handayani (2005) membuktikan bahwa ekstrak daun selasih mempunyai daya repelen positif terhadap nyamuk Anopheles aconitus. Aktivitas larvasida dari tanaman selasih juga telah dicatat oleh Adnyana
(2005), namun belum diketahui spesies nyamuk yang digunakan. Penelitian ini dilakukan lebih spesifik dengan menggunakan ekstrak daun selasih sebagai larvasida bagi larva nyamuk Anopheles aconitus.

Masalahnya adalah bagaimana mortalitas dan pertumbuhan larva nyamuk Anopheles aconitus setelah diberi perlakuan ekstrak daun selasih. Pada konsentrasi ekstrak berapa efektif mempengaruhi mortalitas dan pertumbuhan larva nyamuk Anopheles aconitus. Karena itu perlu dilakukan penelitian bagaimana mortalitas dan pertumbuhan larva nyamuk Anopheles aconitus akibat pemberian ekstrak daun selasih dan pada konsentrasi ekstrak berapa efektif meningkatkan mortalitas dan menurunkan pertumbuhan larva.

\section{BAHAN DAN METODE}

Pembuatan ekstrak daun selasih (Oscimum basilicum)

Daun selasih diperoleh dari sisa-sisa pemakaman dari pemakaman umum Bergota, dibersihkan dari ranting dan kotoran ikutan, kemudian dikering anginkan selama kurang lebih 
3-4 hari. Kemudian daun selasih kering di destilasi selama 2 jam hingga diperoleh ekstrak kasar (campuran air dan minyak), ekstrak kasar inilah yang digunakan untuk pengujian.

\section{Pengadaan hewan uji}

Hewan uji yang digunakan adalah larva nyamuk Anopheles aconitus instar I untuk uji pertumbuhan dan instar III untuk uji mortalitas. Larva diperoleh dari Balai Besar Penelitian dan Pengembangan Vektor dan Reservoir Penyakit (B2P2VRS) Salatiga.

Uji mortalitas larva nyamuk akibat pemberian ekstrak daun selasih

Pengujian terhadap mortalitas larva dan toksistas ekstrak dilakukan dengan uji hayati (bioassay) dalam 3 tahapan. Tahapan pertama adalah uji pendahuluan untuk menentukan kisaran konsentrasi ambang atas ( $\mathrm{LC}_{95}-24$ jam) dan ambang bawah ( $\mathrm{LC}_{5}-48$ jam). Tahapan kedua adalah uji toksisitas ( $\mathrm{LC}_{50}-48$ jam) untuk mengetahui efektifitas ekstrak. Tahapan ketiga adalah uji mortalitas untuk mengkaji bagaimana pola mortalitas larva nyamuk akibat pemberian ekstrak daun selasih. Semua tahapan uji hayati menggunakan lima tingkatan konsentrasi ekstrak dan satu kontrol (Weber, 1993). Untuk setiap konsentrasi perlakuan digunakan 20 ekor larva yang dimasukkan kedalam gelas berisi $60 \mathrm{ml}$ larutan dengan berbagai konsentrasi perlakuan. Perhitungan tingkatan konsentrasi berdasarkan formulasi Hubert (1979). Perhitungan nilai toksisitas menggunakan Analisis Probit (Komisi Pestisida Pertanian, 1995).

Uji pertumbuhan larva nyamuk akibat pemberian ekstrak daun selasih

Pengujian terhadap pertumbuhan populasi larva berdasarkan metode Zhang et al. (1993 dalam Yusnarti, 1996). Konsentrasi ekstrak yang diujikan adalah lima konsentrasi sub letal yaitu konsentrasi dibawah nilai $\mathrm{LC}_{50}-48$ jam dan kontrol. Setiap gelas berisi $60 \mathrm{ml}$ bahan uji setiap konsentrasi perlakuan dan 20 ekor larva instar I. Parameter pertumbuhan populasi larva uji yang digunakan adalah GI (Growth Index) dan RGI (Relative Growth Index)

$$
\begin{aligned}
& \mathrm{GI}=\frac{[\mathrm{n}(\mathrm{I} \max ) \mathrm{x} I \max ]+\sum\left[\mathrm{n}^{\prime}(\mathrm{i}) \mathrm{x}(\mathrm{i}-1)\right.}{\mathrm{N} \text { x i max }} \\
& \text { GI }=\text { Indeks pertumbuhan } \\
& \mathrm{i} \quad=\text { nomor stadium } \\
& \mathrm{n}(\mathrm{i} \max )=\text { jumlah larva yang hidup pada stadium i max } \\
& \text { n'(i) = jumlah larva yang mati pada stadium } \mathrm{i} \\
& \text { i } \max =\text { stadium tertinggi yang dicapai larva } \\
& \mathrm{N} \quad=\text { jumlah total larva dalam kelompok uji } \\
& \text { RGI }=\underset{\text { GI kontrol }}{\text { GI perlakuan }}
\end{aligned}
$$

Uji kandungan metabolik sekunder ekstrak daun selasih

Pengujian terhadap kandungan metabolik sekunder ekstrak daun selasih dilakukan di Laboratorium Instrumen Kimia Organik F MIPA UGM dengan uji GCMS (Gass Cromatography Mass Spectroscopic Technique).

\section{HASIL DAN PEMBAHASAN}

\section{Mortalitas larva nyamuk akibat pemberian ekstrak daun selasih \\ Uji Pendahuluan}

Hasil pengujian uji pendahuluan (Tabel 1) menunjukkan bahwa nilai mortalitas larva semakin meningkat sejalan dengan meningkatnya konsentrasi ekstrak. Ekastrak daun selasih ini mampu menyebabkan mortalitas larva nyamuk $A$. aconitus $45 \%$ pada konsentrasi ekstrak $0,5 \%$ dan mortalitas larva nyamuk A. aconitus $95 \%$ pada konsentrasi $8 \%$. Dengan demikian diperoleh nilai ambang bawah pada konsentrasi ekstrak 0,5\% dan nilai ambang atas pada konsenstrasi ekstrak $8 \%$. 
Tabel 1. Mortalitas larva Anopheles aconitus setelah perlakuan berbagai tingkat konsentrasi ekstrak daun selasih Oscimum basilicum selama 48 jam.

\begin{tabular}{cccc}
\hline $\begin{array}{c}\text { Konsentra } \\
\text { si ekstrak } \\
\text { uji } \\
(\% \text { v/v })\end{array}$ & $\begin{array}{c}\text { Jumlah } \\
\text { larva uji }\end{array}$ & $\begin{array}{c}\text { Total } \\
\text { mortalitas } \\
\text { larva uji }\end{array}$ & $\begin{array}{c}\text { Persentase } \\
\text { Mortalitas } \\
\text { larva uji (\%) }\end{array}$ \\
\hline $0.0 \%$ & 20 & 1 & 5 \\
$0.5 \%$ & 20 & 9 & 45 \\
$1.0 \%$ & 20 & 11 & 55 \\
$2.0 \%$ & 20 & 11 & 55 \\
$4.0 \%$ & 20 & 14 & 70 \\
$8.0 \%$ & 20 & 19 & 95 \\
\hline
\end{tabular}

\section{Uji Sesungguhnya}

Hasil pengujian uji sesungguhnya (Tabel 2) menunjukkan bahwa ekstrak daun selasih berpengaruh nyata terhadap mortalitas larva nyamuk $A$. aconitus. Hal ini ditunjukkan pada konsentrasi uji terendah $0,87 \%$ sudah memberikan pengaruh yang nyata terhadap mortalitas larva nyamuk A. aconitus. Berdasarkan Uji MannWhitney, diperoleh hasil bahwa semua konsentrasi ekstak daun selasih yang diujikan memberi pengaruh nyata terhadap larva nyamuk $A$. aconitus.

Ekstrak daun selasih yang diuji nampaknya selain sebagai racun perut dan racun kontak, secara tidak langsung juga berfungsi sebagai fumigan, karena bau yang ditimbulkan yang diduga akibat senyawa bioaktif yang menguap sebagai gas. Menurut Untung (1993) fumigan merupakan insektisida yang mudah menguap menjadi gas dan masuk ke dalam tubuh serangga melalui sistem pernafasan atau sistem trakea yang kemudian diedarkan ke seluruh tubuh. Matsumura (1975) menyatakan insektisida yang mempengaruhi sistem pernafasan serangga berperan menghambat enzim pernafasan berupa penghambatan sistem transpor elektron dan fosforilasi oksidatif. Tarumingkeng (1992) mengungkapkan bahwa penghambatan sistem transpor elektron ditandai dengan paralisis dan berakhir dengan kematian, hal ini karena senyawa bioaktif menyerang proses transpor elektron NPNH dan NADH.

Senyawa bioaktif yang terkandung dalam ekstrak daun selasih bekerja secara simultan untuk mematikan larva nyamuk $A$. aconitus sehingga belum diketahui secara pasti jenis senyawa yang berpengaruh secara spesifik terhadap salah satu jenis racun, baik sebagai racun perut, racun kontak maupun fumigan. Sesuai dengan yang dikemukakan Priyadi, dkk (2001) bahwa pemanfaatan ekstrak kasar merupakan salah satu keuntungan dalam pemekaian insektisida botani, karena senyawa-senyawa bioaktif yang sudah ataupun belum diketahui jenis dan manfaatnya dapat saling bersinergi meningkatkan stabilitas serta potensi ekstrak daun selasih sebagai insektisida botani.

Tabel 2. Mortalitas larva Anopheles aconitus setelah perlakuan berbagai tingkat konsentrasi ekstrak daun Oscimum basilicum selama 72 jam

\begin{tabular}{cccc}
\hline $\begin{array}{c}\text { Konsentrasi } \\
\text { ekstrak uji } \\
(\% \text { v/v })\end{array}$ & $\begin{array}{c}\text { Jumlah } \\
\text { larva uji }\end{array}$ & $\begin{array}{c}\text { Total } \\
\text { mortalitas } \\
\text { larva uji }\end{array}$ & Rerata \\
\hline $0.00 \%$ & 60 & 0 & $0.00^{\mathrm{a}}$ \\
$0.87 \%$ & 60 & 15 & $5.00^{\mathrm{b}}$ \\
$1.51 \%$ & 60 & 15 & $5.00^{\mathrm{b}}$ \\
$2.63 \%$ & 60 & 23 & $7.67^{\mathrm{bc}}$ \\
$4.58 \%$ & 60 & 27 & $9.00^{\mathrm{c}}$ \\
$7.97 \%$ & 60 & 37 & $12.33^{\mathrm{cd}}$ \\
\hline
\end{tabular}

Hasil pengujian efektifitas atau toksisitas ekstrak daun selasih terhadap larva nyamuk $A$. aconitus (Tabel 3) yang ditunjukkan dengan nilai $\mathrm{LC}_{50}-48$ jam yaitu pada konsentrasi $5,01 \%$ yang artinya bahwa pada konsentrasi ekstrak daun selasih $5,01 \%$ tersebut mampu menyebabkan kematian larva nyamuk $A$. aconitus yang diujikan sebesar $50 \%$. Kematian larva nyamuk ini disebabkan oleh senyawa bioaktif yang terkandung di dalam ekstrak daun selasih berperan sebagai toksikan. Senyawa bioaktif yang terkandung didalam ekstrak daun selasih antara lain eugenol dan methyl chavicol, hal ini sesuai dengan yang dikemukakan oleh Adnyana (2005) bahwa eugenol dan methyl chavicol bertanggung jawab terhadap aktivitas larvasida. Apriana (2008) melaporkan efektifitas ekstrak daun selasih terhadap larva nyamuk Aedes aegypti, diperoleh nilai $\mathrm{LC}_{50}-24$ jam ekstrak daun selasih terhadap larva nyamuk tersebut terjadi pada konsentrasi $7,13 \%$. 
Tabel 3. Efektifitas (toksisitas) ekstrak daun selasih Oscimum basilicum terhadap larva Anopheles aconitus

\begin{tabular}{ccccc}
\hline $\begin{array}{c}\text { No } \\
\text { K }\end{array}$ & $\begin{array}{c}\text { Konsent } \\
\text { rasi } \\
\text { ekstrak } \\
(\%)\end{array}$ & $\begin{array}{c}\text { Jumlah } \\
\text { hewan } \\
\text { uji }\end{array}$ & $\begin{array}{c}\text { Persentase } \\
\text { mortalitas } \\
\text { larva }(\%)\end{array}$ & \\
\cline { 1 - 4 } 1 & 0.00 & 60 & 0.0 & Nilai LC \\
$\mathbf{5 0 - 7 2}$ jam \\
2 & 0.87 & 60 & 15 & \\
3 & 1.51 & 60 & 15 & $\mathbf{5 . 0 1 \%}$ \\
4 & 2.63 & 60 & 23 & \\
5 & 4.58 & 60 & 27 & \\
6 & 7.97 & 60 & 37 & \\
\hline
\end{tabular}

Uji Pertumbuhan larva nyamuk Anopheles aconitus pada konsentrasi sub lethal ekstrak daun selasih Oscimum bassilicum

Tabel 4. Nilai GI dan RGI hasil uji pertumbuhan larva nyamuk Anopheles aconitus pada pemberian ekstrak daun selasih

\begin{tabular}{|c|c|c|c|c|c|c|c|c|c|c|c|c|}
\hline \multirow{2}{*}{$\begin{array}{c}\text { Kons } \\
\text { ekastrak } \\
(\%)\end{array}$} & \multicolumn{2}{|c|}{ L 1} & \multicolumn{2}{|c|}{ L 2} & \multicolumn{2}{|c|}{ L 3} & \multicolumn{2}{|c|}{ L 4} & \multirow{2}{*}{$\begin{array}{c}\text { Jml } \\
\text { larva } \\
\text { hidup }\end{array}$} & \multirow[b]{2}{*}{$\begin{array}{c}\text { Jm } \\
\text { l } \\
\text { lar } \\
\text { va } \\
\text { ma } \\
\text { ti }\end{array}$} & \multirow[b]{2}{*}{ GI } & \multirow[b]{2}{*}{$\begin{array}{c}\text { RGI } \\
(\%)\end{array}$} \\
\hline & $\mathbf{H}$ & $\mathbf{M}$ & $\mathbf{H}$ & $\mathbf{M}$ & $\mathbf{H}$ & $\mathbf{M}$ & $\mathbf{H}$ & $\mathbf{M}$ & & & & \\
\hline 0.00 & 20 & 0 & 20 & 0 & 16 & 4 & 16 & 0 & 16 & 4 & 0.90 & 100 \\
\hline 0.16 & 20 & 0 & 20 & 0 & 15 & 5 & 15 & 0 & 15 & 5 & 0.88 & 97 \\
\hline 0.31 & 20 & 0 & 19 & 1 & 12 & 7 & 12 & 0 & 12 & 8 & 0.79 & 88 \\
\hline 0.93 & 20 & 0 & 16 & 4 & 11 & 5 & 11 & 0 & 11 & 9 & 0.73 & 81 \\
\hline 1.29 & 20 & 0 & 16 & 4 & 11 & 5 & 11 & 0 & 11 & 9 & 0.73 & 81 \\
\hline 1.53 & 20 & 0 & 17 & 3 & 11 & 6 & 11 & 0 & 11 & 9 & 0.73 & 81 \\
\hline
\end{tabular}

Berdasarkan Tabel 4 nampak bahwa nilai GI dan nilai RGI semakin menurun sejalan dengan semakin meningkatnya konsentrasi ekstrak yang diujikan. Konsentrasi ekstrak yang tinggi akan menyebabkan nilai GI rendah, yang disebabkan karena larva mati pada instar-instar awal sehingga tidak mampu berganti kulit untuk tumbuh ke tahapan instar selanjutnya. Sedangkan pada konsentrasi ekstrak yang rendah, maka nilai GI tinggi karena larva uji tetap hidup pada instarinstar awal sehingga mampu berganti kulit dan mampu melanjutkan ketahapan instar berikutnya.

Senyawa toksik yang masuk dalam tubuh serangga dapat mengakibatkan turunnya laju pertumbuhan serangga. Diduga akibat kegagalan serangga dalam melakukan respon terhadap pemenuhan pakan karena makanannya mengandung senyawa alelokimia. Senyawa alelokimia (metabolit sekunder) yang terkandung dalam ekstrak daun selasih merupakan golongan terpenoid, dan menurut Schoonhoven (1982 dalam Yusnarty, 1996) bahwa senyawa terpenoid sangat berpotensi sebagai penghambat makan pada sejumlah serangga.

Uji kandungan metabolit sekunder ekstrak daun selasih

Hasil uji metabolit sekunder dengan GCMS ekstrak daun selasih seperti tercantum dalam Tabel 5 .

Tabel 5. Kandungan metabolit sekunder pada ekstrak daun selasih

\begin{tabular}{lc}
\hline Metabolit sekunder & Pros Kandungan \% (v/v) \\
\hline 1. Methyl chavicol & 81,10 \\
2. Methyl eugenol & 12,70 \\
3. Methoxycinnamaldehyde & 1,89 \\
4. Eucalyptol & 0,61 \\
5. Germacrene & 0,55 \\
\hline
\end{tabular}

Menurut Adnyana (2005) methyl chavicol berpotensi untuk larvasida, sedangkan menurut Kardiman (2003ab) methyl eugenol berperan sebagai penarik (atraktan) bagi lalat buah, antimakan bagi Artemia (Anonim, 2005d). Eucalyptol dapat digunakan sebagai atraktan lebah madu, juga sebagai toksikan bagi kutu daun (Anonim, 2005a) sedangkan Germacrene berperan dalam antimikroba dan feromon bagi serangga (Anonim, 2005b).

\section{KESIMPULAN}

1. Ekstrak daun selasih Oscimum basilicum mampu meningkatkan mortalitas dan menurunkan pertumbuhan larva Anopheles aconitus.

2. Konsentrasi efektif ( $\mathrm{LC}_{50}-48$ jam) ekstrak daun Oscimum basilicum untuk mortalitas adalah $5,01 \% \quad(\mathrm{v} / \mathrm{v})$ serta dengan konsentrasi $\quad 0,93 \% \quad(\mathrm{v} / \mathrm{v}) \quad$ efektif menurunkan pertumbuhan larva nyamuk Anopheles aconitus.

\section{DAFTAR PUSTAKA}

Adnyana, K. dan Firmansyah. 2005. Kemangi versus selasih dari pecel lele, obat herba sampai parfum. 
http://www.pikiranrakyat.com/cetak/2006/012006/ 26/cakrawala/lainnya07.htmp pecellele.6 November 2007.

Anonim, $2005 \mathrm{a}$. Eucalyptol http://en.wikipedia.org/wiki/Eucalyptol. 6 November 2007

Anonim, 2005b. Germacrene http://en.wikipedia.org/wiki/Germacrene. 19 Pebruari 2008

Anonim, 2005c. Methyl chavicol http://en.wikipedia.org/wiki/Methyl chavicol. 6 November 2007

Anonim, 2005d. Methyl Eugenol http://en.wikipedia.org/wiki/Methyl eugenol. 6 November 2007

Apriana, S. 2008. Pengaruh ekstrak daun Selasih terhadap mortalitas dan pertumbuhan larva nyamuk Aedes aegypti. Jurusan Biologi FMIPA UNDIP

Budiarto. 2000. Pengaruh Ekstrak Kulit Buah Jeruk Siam Citrus nobilis L. Terhadap Mortalitas dan Perkembangan Hama Bubuk Beras Sithopilus oryzae L. Skripsi. Fakultas MIPA UNDIP. Semarang .

Dinata, S. 2005. Tanaman sebagai pengusir nyamuk. http:///www.Pikiran rakyat.Com. 21 November 2006

Handayani, R. 2005. Daya tolak minyak atsiri selasih terhadap nyamuk Anopheles aconitus. Skripsi FKM UNDIP, Semarang

Hubert, J.J. 1979. Bioassay. Kendall Hunt Publishing Company, USA.
Kardiman, A. 2003a. Mengenal lebih dekat Selasih tanaman keramat multimanfaat. Agromedia Pustaka, Jakarta.

Kardiman, A. 2003b. Mengenal lebih dekat tanaman pengendali lalat buah. Agromedia Pustaka, Jakarta.

Komisi Pestisida Pertanian. 1995. Metode standar pengujian efikasi pestisida.Departemen Pertanian Republik Indonesia

Priyadi, S. S. Hadiwiyoto, dan S. Anggraheni. 2001. Komponen aktif daun nimba terhadap penghambatan aktivitas makan Plutella xylostella. Agrosains Vol. 14 (3) : 261-272

Tarumingkeng, R.C. 1992. Insektisida : sifat, mekanisme, kerja, dan dampak penggunaannya. Universitas Kristen Krida Wacana, Jakarta.

Untung, K. 1993. Pengantar Pengelolaan Hama Terpadu. Gadjah Mada University Press, Yogyakarka

Weber, C.I. 1993. Methods for Measuring the acute toxicity of effluents and receiving waters from freshwater and marine organism. Environmental monitoring systems laboratory. Office of Research and Development, Cicinnati.

Yusnarti,Y. 1996. Pengaruh ekstrak biji Annona muricata L. terhadap indeks nutrisi, kelulushidupan, pertumbuhan dan perkembangan larva Heliothis armigera. ITB Bandung 